\title{
Foucher Technique for Fractures Dthe Neck in Lfifth Metacarpiano. Case Report Hospital Alcivar 2015 - 2017
}

\section{Roque Alcivar ${ }^{1 *}$, Mario Ruiz Manzo ${ }^{1}$, Juan Guevara Garay ${ }^{1}$, Harold Secaira Figueroa ${ }^{1}$ and Hugo Villarroel Rovere ${ }^{2}$ ${ }^{1}$ Medical Specialist Orthopedics and Traumatology Hospital Alcívar \\ ${ }^{2}$ Director of Postgraduate Orthopedics and Traumatology Hospital Alcívar \\ *Corresponding Author: Roque Alcivar, Medical Specialist Orthopedics and Traumatology Hospital Alcívar.}

Received: September 30, 2019; Published: October 29, 2019

DOI: 10.31080/ASOR.2019.02.0119

\begin{abstract}
Introduction: The objective of this work is to evaluate the functional results of a continuous series of patients with a fractured fifth metacarpal, treated by Foucher'stechnique.

Materials and Methods: The study is carried out between January 2015 and December 2017. The inclusion criteria for this study were: patients of any age,fractures at the level ofthe fifth metacarpal cuello and cases with angulation palmar $>30$ " and $>5 \mathrm{mmshort-}$ ening. They were excluded: head fractures of another metacarpal, multiple fractures and s presenting boneexposure. The functional subjective evaluation of the results was carried out with the DASH questionnaire.

Results: 32 patients were evaluated with an average follow-up of 12 months. In all cases the fractures consolidated. The DASH average was 3.2 points. No complications were reported.

Conclusion: The treatment of this type of fractures is diverse, we recommend this technique as a fast and safe method without complications.
\end{abstract}

Keywords: Metacarpal; Head; Foucher

\section{Introduction}

Fifth metacarpal fractures of the neck (commonly referred to as bad boxer fractures) are the most common type of metacarpal fractures [1-3], report as $25 \%$ of all metacarpal fractures. Re have $38 \%$ of all hand fractures since the neck is the weakest point in metacarpals $[4,5]$. Of all upper limb fractures, metacarpal neck fractures of the little finger make up $5 \%$ of the overall total [6]. Neck fractures of the fifth metacarpal are usually associated with aggressive behaviors; these fractures are typically caused by a longitudinal compression force of the knuckles when the hand is in a clenched fist posture [7].
It is commonly observed in the dominant hand of active young male patients [8-10]. Most of these fractures are not displaced or minimally displaced without a rotational deformity, and can be treated by conservative treatment with a good functional result $[11,12]$. However, it is recommended to have surgery for severely displaced fracture or angulation fly with severe rotational deformity, cases with angulation palmar of $>30$ and shortening of $>$ $5 \mathrm{~mm}$ which would greatly affectthe function of hand [13] so they deserve surgical fixation. Surgical fixation is also recommended for such fractures to prevent poor rotation of the pinky which will lead to the overlapping of the fingers on a closedfist [14]. 


\section{Materials and Methods}

Between January 2015 and December 2017, clinical records were collected from 36 patients who were surgically treated with Foucher's technique. Among the 36 patients included in the study, 32 included inclusion criteria, plus cases with angulation palm of $>30$ and shortening of $>5 \mathrm{~mm}$, and excluded 2 patients who had a broken neck in the 2nd metacarpal and 2 patients who also had a fracture of another metacarpal. Of the 32 patients, 33 fractures were evaluated, as one patient had bilateral fracture; they weretreated by different orthopedists. The average follow-up time was 12 months (range from 6 to 15 months).

The functional subjective evaluation of the results was carried out by means of the DASH questionnaire (which gives values on a scale of 0 to 100 , with 0 being the best result).

\section{Results}

Of the 32 patients with neck fracture of the 5th metacarpal, 31 patients were men and 1 female (Figure 1); 28 fractures were located on the right side, while 5 were located on the left side (Figure 2 ); direct trauma and the falls were the most common production mechanisms for fractures (Figure 3); the average age was 37 years (range 12 - 79 years).

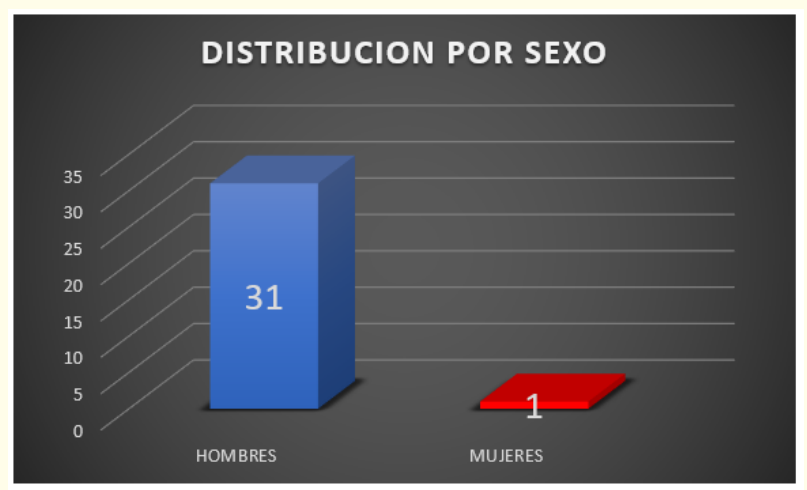

Figure 1: Alcívar Hospital medical records. Made by Roque Alcívar León.

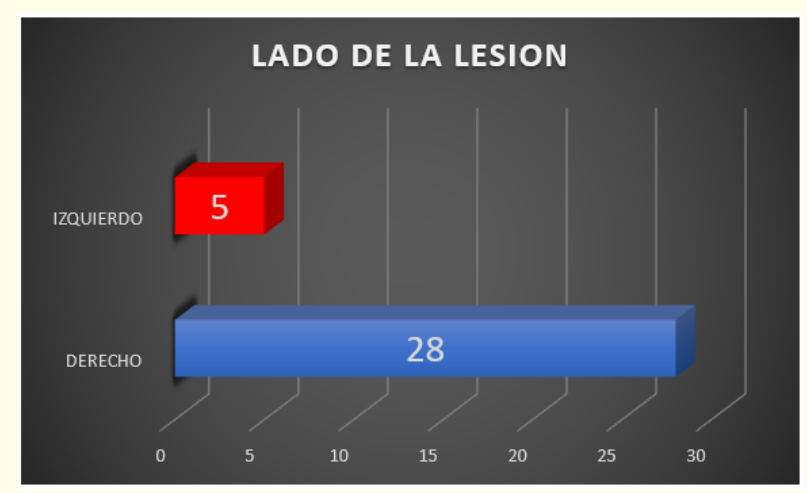

Figure 2: Alcívar Hospital medical records. Made by Roque Alcívar León.

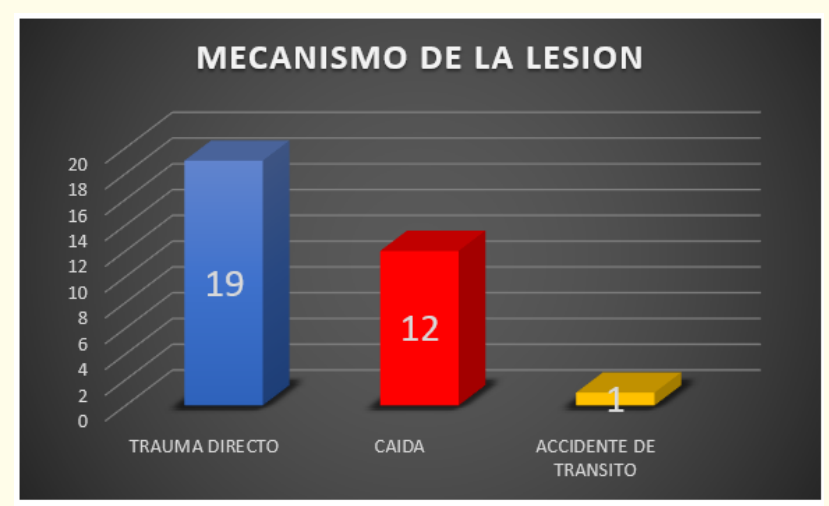

Figure 3: Alcívar Hospital medical records. Made by Roque Alcívar León.

The final average DASH questionnaire was 1.93 (range 0 to 4.5). All patients reintegrated into their normal work activities after implant removal in approximately 4 - 6weeks.

No complications or trans operative accidents were reported or during the immediate postoperative period, reflective sympathetic dystrophy. We do not find infections or exposures of osteosynthesis material or sequelae such as claw deformity. 


\section{Discussion}

Hand fractures can be complicated with deformity by lack of treatment, stiffness from overtreatment or deformity and stiffness from poor treatment [15].

E. Civar and cabbages [16]. indicate that fractures with minimal displacement or aride have a good prognosis; on the other hand, fractures that have amajor separation or angulation they have to be corrected conservatively, if this is not possible, open reduction and fixation is done. Joint fractures must be corrected by galens that are aware of this subspecialty. It also indicates that immobilization should not be extended beyond three weeks, because rigidto-die rehabilitation is difficult. However, immobilization should never be done in extension, but in ananatomical position. It also reports the importance of avoiding the rotation of the fragment as this is its worst complication.

K. Shen and cabbages [8], in their study 69 young patients between 12 and 17 years of age, treated by endomidulated interrogation with Foucher technique, used TEN nail obtaining favorable results with a DASH functional scale of 1.7 on average, all fractures consolidated approximately 8 weeks, where osteosynthesis material was removed upon confirmation of bone consolidation by radiology and no complications were reported during follow-up.

Likewise, S. Galal., et al. [4], followed up on 30 patients between 20 and 40 years of age, treated using the Foucher technique, using Kirschner needles where all fractures consolidated between 8 weeks with radiological follow-up, subsequently removing the osteosynthesis material; indicated that 5 patients with complications (clove protrusion, superficial infection, secondary lesion of the ulnar nerve dorsal branch)occurred, in addition indicated an average DASH functional scale of 5 .

In the publication of S. Cha and cabbage [17], report 26 patients between 16 and 44 years of age, treated with the technique under study, using Kirschner's needles as a method of fixing, show as a result consolidation of all their withdrawn fractures by confirmation with radiological study, with an average DASH functional scale of 1.7 and no complications occurred at the end of follow-up.

S. Akinleye and cabbage [18], conducted a comparative study of four fixing techniques for the treatment of such fractures in cadav- eric specimens, including antegrade fixation (Foucher technique), cross-sectional fixation, fixation retrograde and retrograde fixation with cross-pins, mentioning that in each technique it shows an injury of at least one neurotendinous structure at the time of passage of the osteosynthesis material. None of the percutaneous techniques described for the treatment of neck fractures of the fifth metacarpal eliminate the potential for damage to surrounding tendons or nerves. Each technique has risk structures that the treating surgeon should know to anticipate possible complications and advise patients accordingly.

L. Amsallen and cabbages [19], in its report on 30 patients aged 19 to 55, treated with Kirschner needles using the Foucher technique, indicate bone consolidation of their fractures by withdrawing them at approximately 3 weeks and with X-ray-confirmed bone consolidation, indicated a 3.5-average DASH scale, as well as no complications at the end of follow-up.

In a study conducted by H. Boussakri., et al. [20], including 28 patients between 15 and 61 years of age, treated with Kirschner needles using the Foucher technique, indicate consolidation of fractures and removal of osteosynthesis material between 4 and 6 weeks prior confirmation of bone consolidation through radiographic studies, in addition to the average DASH functional scale of 2.5 , in the same way does not report complications at the end of follow-up.

In a study conducted by A. de Goes y cols., he states that, within the imaging studies, theoblique X-rays at 30degrees of supination provided the best view of the bone and the least variation in the actual displacement value of fractures of the fifth metacarpal bone [21].

In our study, as in most others we do not present complications at the end of follow-up, Kirschner's pin was removed between 4 and 6 weeks, once bone $\mathrm{x}$-ray consolidation has been demonstrated; but all the authors agree that osteosynthesis material should be removed once bone consolidation is confirmed by x-rays to obtain favorable results.

This work has disadvantages in that few patients are involved and that it is a retrospective analysis, however, we have highlighted the merits of a very simple technique that saves surgical time, 
properly stabilizes the neck fracture metacarpal, promotes early mobilization, lower complication rates and generally achieves a satisfactory result in most patients. More extensive and prospective studies may be required to validate the technique.

\section{Conclusion}

The neck fractures of the fifth metacarpal, has different treatment, in this study we recommend that this minimally invasive percutaneous nail be unique in all the fractures of the boxers, especially when there is swelling severe hand, with good functional results and low morbidity.

In addition, the surgeon has to consider the surrounding anatomy to avoid associated injuries, although they are almost zero, but you have to be aware to avoid the present.

\section{Bibliography}

1. S Zong y cols. "Treatments for the Fifth Metacarpal Neck Fractures A Network Meta-analysis of Randomized Controlled Trials". Medicine 95.11 (2016): e3059.

2. Ozturk I., et al. "Effects of the melting angle on functional results after nonsurgical treatment for the neck fracture of the fifth metacarpal". Injury 39 (2008): 1464-1466.

3. Gudmundsen TE and Borgen L. "Fractures of the fifth metacarpal”. Radiol Acta 50 (2009): 296-300.

4. S Galal y cols. "Transverse Pinning Versus Intramedullary Pinning in Fifth Metacarpal's Neck Fractures: A Randomized Controlled Study with PatientReported Outcome". Journal of Clinical Orthopaedics and Trauma 8.4 (2017): 339-343.

5. Henry MH. "Fractures of the proximal phalanx and metacarpals in the hand: preferred methods of stabilization". The Journal of the American Academy of Orthopaedic Surgeons 16.10 (2008): 586-595.

6. Schadel-Hopfner M., et al. "Aninteal anrubal antherele or percutaneous retrograde cross-grip for neck fractures displaced from the fifth metacarpal?". Archives of Orthopaedic and Trauma Surgery 127 (2007): 435-440.

7. Metacarpal fractures of Soong M., et al. "Ring and pinkie: mechanisms, locations and x-ray parameters". The Journal of Hand Surgery 35 (2010): 1256-1259.

8. K Sheng y cols. "Outcome of antegrade intramedullary fixation for juvenile fifth metacarpal neck fracture with titanium elastic nail". Experimental and Therapeutic Medicine 13 (2017): 2997-3002.

9. Arafa M., et al. "Immediate mobilization of the neck fractures of the fifth metacarpal”. Injury 17 (1986): 277-278.
10. de Jonge JJ., et al. "Fractures of the metacarpals. A retrospective analysis of incidence and aetiology and a review of the English-language literature". Injury 25.6 (1994): 365-369.

11. Harris AR., et al. "Metacarpal neck fractures: results of treatment with traction reduction and gypsum immobilization". Hand (NY) 4 (2009): 161-164.

12. Poolman RW., et al. "Conservative treatment for fifth (small finger) metalcarp neck fractures closed". Cochrane Database System Review (2005): CD003210.

13. Low CK., et al. "A cadaver study of the effects of dorsal angulation and shortening of the metacarpal shaft on the extension and flexion force ratios of the index and little fingers". The Journal of Hand Surgery British 20.5 (1995): 609-613.

14. Freeland AE., et al. "Operative treatment of common displaced and unstable fractures of the hand". Journal of Bone and Joint Surgery 83A.6 (2001): 928-945.

15. Freeland AE and Orbay JL. "Extraarticular hand fractures in adults: a review of new developments". Clinical Orthopaedics and Related Research 445 (2006):133-145.

16. E Civar and cabbages. Algorithm in the treatment of Orthopedic Trauma; fracture of the four medial metacarpals 21 (2002): 227-234.

17. S Cha y cols. "Antegrade Intramedullary Pinning in Subacute Fifth Metacarpal Neck Fracture After Failed Conservative Treatment A Prospective Comparative Study with Acute Fracture". Annals of Plastic Surgery 80.4 (2018): 347-352.

18. S Akinleye y cols. "Iatrogenic Injuries in Percutaneous Pinning Techniques for Fifth Metacarpal Neck Fractures, Mano (NY) (2017): 1558944717731858.

19. L Amsallem y cols. "Simplified internal fixation of fifth metacarpal neck fractures". Orthopaedics and Traumatology Surgery and Research (2017).

20. H Boussakri y cols. "Fractures of the neck of the fifth metacarpal bone, treated by percutaneous intramedullary nailing: surgical technique, radiological and clinical results study (28 cases)". Pan African Medical Journal 18 (2014):187.

21. A de Goes y cols. "What is the real angle of deviation of metacarpal neck fractures on oblique views? A radiographic study". Revista Brasileira de Ortopedia 51.2 (2016):150-156.

\section{Volume 2 Issue 11 November 2019}

(C) All rights are reserved by Roque Alcivar., et al. 